\title{
Development is not the same as ageing: the relevance of puberty to health of adolescents
}

\author{
Candace Currie ${ }^{1}$
}

Received: 18 January 2019/Accepted: 23 January 2019/Published online: 21 March 2019

(C) Swiss School of Public Health (SSPH+) 2019

In much academic writing on matters of adolescent public health, age is treated as a proxy for developmental stage, and yet the two are very different concepts and this lack of distinction neglects important biological processes that impact the well-being of young people. Large-scale surveys of adolescents frequently describe differences in the health and risk behaviour, as well as a wide range of health measures, as related to age (Currie et al. 2008, 2012a). Between the ages of 11 and 15 years, adolescents are immersed in a complexity of changes to their physical selves, cognitive function, emotional range, impulsivity, desire for risk taking and hormonal function (Patton and Viner 2007). These changes affect their health-related behaviour, well-being, social and gender identity, social relations and ability to concentrate and learn.

However, the timing and pace of pubertal development varies significantly between the sexes, and between individual girls and boys, depending on a wide range of personal, social and environmental factors (Walvoord 2010). Genetics also play a part as do biological determinants such as adiposity (Currie et al. 2012b), as well as environmental oestrogens and toxins from substances such as pesticides and other chemicals that they consume, inhale or are in contact with through their skin. The sensitivity of the adolescent body to environmental chemicals is as yet not well understood. Nevertheless, there is growing evidence that puberty is starting at younger ages with exposure to harmful environmental substances causing endocrine disruption, as one candidate explanation.

The stage of puberty that individuals have reached at a particular age in the second decade of life is a key factor in

Candace Currie

candace.currie@gcu.ac.uk

1 Global Adolescent Health and Behaviour Research Unit (GAHBRU), GCU London, 40 Fashion Street, London E1 6PX, UK their mental, physical and emotional well-being (Oldehinkel et al. 2011). At age 11 some girls may be well developed physically, with breast development and reproductive development well advanced. In the same classroom will be girls who, in contrast, still have the physical appearance of a child. At age 13 some boys are small in stature having not experienced a growth spurt, their voices are unbroken, and their faces hairless, while others have had a spurt in height, have developed a muscular physique, show signs of a moustache and have a deepened voice. These differences in appearance that puberty may imbue have an effect on how adolescents feel about themselves and how others, including the same and opposite sex peers and adults, such as parents and teachers, treat them (Williams and Currie 2000).

Girls who reach puberty early are known to have a host of behavioural characteristics not observed in their age peers who are late developers. They are more likely to have early sex, to begin smoking and drinking, to be concerned about their body weight and to have mental health problems (Kaltiala-Heino et al. 2003; Patton et al. 2004). Early puberty is associated with mental health problems in middle adolescence. Some of these differences equalise by the later teenage years, but others persist through young and later adulthood and studies have shown detectable differences in social status, BMI, body image and mental well-being among women in their forties (Stattin and Magnusson 1990). Boys who mature early have some social and physical advantage over their later developing peers. They are more likely to be popular and excel at sports as well as have earlier romantic relationships. However, recent evidence suggests they also have detrimental psychological outcomes (Mendle and Ferrero 2012).

Among the factors that contribute to earlier puberty are proximal social determinants related to family life. Girls growing up with no father at home, a stepfather at home or living with no parents, especially those in institutional care, have higher odds of early puberty (Steppan et al. under 
review). The explanation for such effects has been theorised to be based on stress, genetics or mediated through BMI. Whatever the mechanism, the complexity of contemporary family life seems to have an important influence on pubertal processes which can accelerate girls' reproductive lives.

Biological factors such as body composition, and in particular, adiposity as well as heritable factors such as mother's genetics, also play a role in the timing of girls' puberty. Girls who have a high BMI are more likely to have early puberty, and between-country differences in BMI have been shown to be associated with betweencountry differences in mean age of menarche (Currie et al. 2012b). While there are shared genetic pathways for having higher BMI and early puberty, this is only part of the explanation. Management of weight during childhood therefore can have an independent effect on pubertal timing.

Far less is known about boys' pubertal timing-its determinants and its consequences-largely for methodological reasons. Menarche has proved to be a simple, reliable marker of girls' puberty, and while there is the equivalent marker of spermarche for boys, it is rarely used in survey research. A few enlightened countries such as Finland have regularly gathered data on spermarche, but in many countries it is felt to be too sensitive a question to ask, by parents and schools. HBSC is one of the very few studies to have gathered data on menarche over several quadrennial surveys enabling analyses that can explore biosocial understandings of adolescent health. What is urgently needed is an equivalent measure to menarche for boys to provide the opportunity for a more in depth exploration of male pubertal processes and how they may impact on male adolescent health and well-being.

\section{References}

Currie C et al (eds) (2008) Inequalities in young people's health: HBSC international report from the 2005/2006 Survey. WHO Regional Office for Europe, Copenhagen

Currie C et al (eds) (2012a) Social determinants of health and wellbeing among young people. HBSC international report from the 2009/2010 survey. Health Policy for Children and Adolescents No. 6, WHO Regional Office for Europe, Copenhagen

Currie C, Ahluwalia N, Godeau E, Gabhainn SN, Due P, Currie DB (2012b) Is obesity at individual and national level associated with lower age at menarche? Evidence from 34 countries in the Health Behaviour in School-aged Children Study. J Adolesc Health 50(6):621-626

Kaltiala-Heino R, Marttunen M, Rantanen P, Rimpelä M (2003) Early puberty is associated with mental health problems in middle adolescence. Soc Sci Med 57(6):1055-1064

Mäkinen M, Puukko-Viertomies LR, Lindberg N, Siimes MA, Aalberg V (2012) Body dissatisfaction and body mass in girls and boys transitioning from early to mid-adolescence: additional role of self-esteem and eating habits. BMC Psychiatry 12(1):35

Mendle J, Ferrero J (2012) Detrimental psychological outcomes associated with pubertal timing in adolescent boys. Dev Rev 32(1):49-66

Oldehinkel AJ, Verhulst FC, Ormel J (2011) Mental health problems during puberty: tanner stage-related differences in specific symptoms. The TRAILS study. J Adolesc 34(1):73-85

Patton GC, Viner R (2007) Pubertal transitions in health. Lancet 369(9567):1130-1139

Patton GC, McMorris BJ, Toumbourou JW, Hemphill SA, Donath S, Catalano RF (2004) Puberty and the onset of substance use and abuse. Pediatrics 114(3):e300-e306

Stattin H, Magnusson D (1990) Paths through life, vol. 2. Pubertal maturation in female development, vol 2. Lawrence Erlbaum Associates Inc., Hillsdale

Steppan M, McEachran J, Whitehead R, Currie C (under review) Family characteristics and the age at menarche

Walvoord EC (2010) The timing of puberty: is it changing? Does it matter? J Adolesc Health 47(5):433-439

Williams JM, Currie C (2000) Self-esteem and physical development in early adolescence: pubertal timing and body image. J Early Adolesc 20(2):129-149

Publisher's Note Springer Nature remains neutral with regard to jurisdictional claims in published maps and institutional affiliations. 